\section{REFERENCES}

1. Batista RJV, Santos JLV, Takeshita N, Bocchino L, Lima PN, Cunha MA. Partial left ventriculectomy to improve left ventricular function in end-stage heart disease. J Card Surg 1996;11:96-7.

2. Batista RJV, Verde J, Nery P, Bochino L, Takeshita N, Bhayana JN, et al. Partial left ventriculectomy to treat end-stage heart disease. Ann Thorac Surg 1997;64:634-8.

3. McCarthy PM, Starling RC, Wong J, Scalia GM, Buda T, Vargo
RL, et al. Early results with partial left ventriculectomy. J Thorac Cardiovasc Surg 1997;114:755-65.

4. Chin TK, Perloff JK, Williams RG, Jue K, Mohrmann R. Isolated noncompaction of left ventricular myocardium: a study of eight cases. Circulation 1990;82:507-13.

5. Fazio S, Sabatini D, Capaldo B, Vigorito C, Giordano A, Guida $\mathrm{R}$, et al. A preliminary study of growth hormone in the treatment of dilated cardiomyopathy. N Engl J Med 1996;334:809-14.

\title{
CYTOLOGIC EXAMINATION OF SURGICAL MARGIN OF EXCISED MALIGNANT PULMONARY TUMOR: METHODS AND EARLY RESULTS
}

\author{
Noriyoshi Sawabata, MD, ${ }^{\mathrm{a}}$ Takashi Mori, MD, ${ }^{\mathrm{b}}$ Keiji Iuchi, MD, ${ }^{\mathrm{b}}$ Hajime Maeda, MD, ${ }^{\mathrm{a}}$ Mitsunori Ohta, MD, ${ }^{\mathrm{a}}$ and
} Osamu Kuwahara, MD, ${ }^{\text {a }}$ Osaka, Japan

Tumor excision is a strategy to treat peripheral pulmonary malignant lesions in high-risk candidates for lobectomy or pneumonectomy and in patients with metastatic tumors. ${ }^{1-3}$ Certain wedge-excised malignant tumors recur at the surgical margin despite histologic evidence of a safe margin. ${ }^{4}$ Even if the histologic examination reveals no evidence of malignancy on the margin of an excised tumor, this is no guarantee that the lung tissue around the excised margin is free from malignant cells, because histologic examination cannot study all aspects of the surgical margin of an excised tumor. Besides, cytologically, we can collect specimens from the whole area of the surgical margin of an excised malignant tumor. The purpose of this study is to demonstrate the method and the early results of cytologic examination on the surgical margins of wedge-excised tumors.

Technique. From April 1996 to May 1998, 35 small peripheral malignant pulmonary nodules (less than $3 \mathrm{~cm}$ in diameter) from 30 patients were excised. The patients, aged 50 to 82 years, included 24 men and 6 women. Seven lesions were subjected to video-assisted thoracoscopic surgery (VATS) and 28 to thoracotomy. Preoperative diagnoses were as follows: 8 undiagnosed lung cancers, 17 lung cancers, and 10 metastatic cancers from colorectal carcinoma.

Cytologic examination of the surgical margin was performed before the cross section was studied to prevent malignant cell contamination. Material for cytologic examination

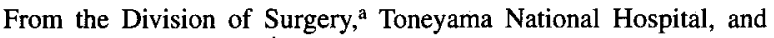
Division of Surgery, ${ }^{b}$ Kinki Central National Hospital for Chest Diseases, Osaka, Japan.

Received for publication Aug 19, 1998; accepted for publication Oct 14, 1998.

Address for reprints: Noriyoshi Sawabata, MD, Division of Surgery, Toneyama National Hospital, 5-1-1 Toneyama, Toyonaka, Osaka, Japan 560-8552.

J Thorac Cardiovasc Surg 1999;117:618-9

Copyright $(1999$ by Mosby, Inc.

$0022-5223 / 99 \$ 8.00+0 \quad \mathbf{1 2 / 5 4 / 9 5 2 9 9}$

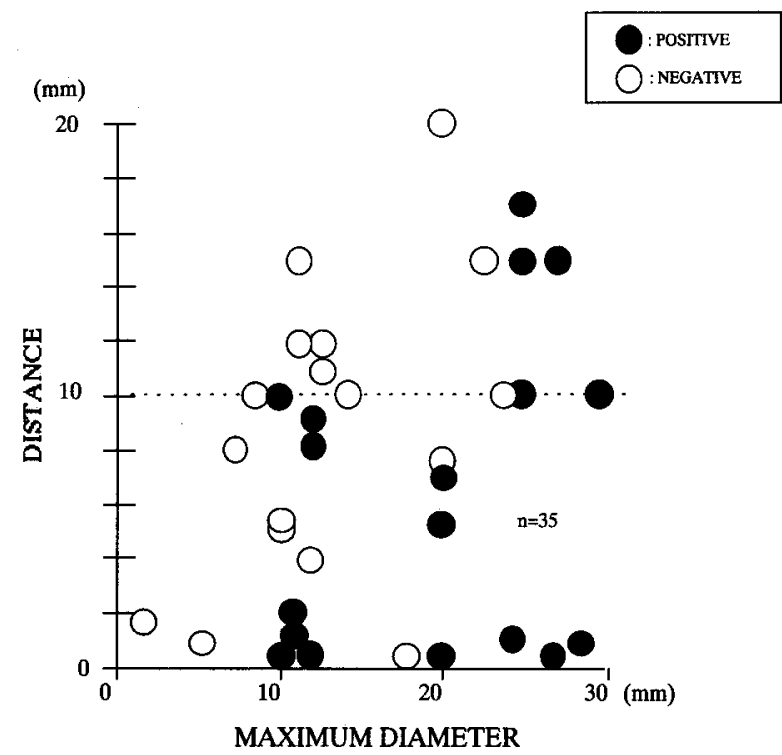

Fig 1. Cytologic diagnosis on surgical margins of wedgeresected malignant tumor. Among 15 samples showing histologically safe marginal distance (more than $10 \mathrm{~mm}$ ), $40 \%$ $(6 / 15)$ of them had cytologically positive surgical margins.

of the surgical margin of wedge-excised lung was harvested with a glass slide. The glass side was run across the staple site at least three times until sufficient material was collected. The harvested sample was spread on another glass slide and fixed by ethanol spray as soon as possible. It took approximately 15 seconds to harvest samples for cytologic examination and 12 minutes to apply the Papanicolaou stain. A cytopathologist was on site and interpreted the slide. After the materials for cytologic examination had been harvested, the wedge-resected specimen was cut and examined grossly and pathologically. Cytologic diagnoses of surgical margins of wedge-resected malignant tumors are described in Fig 1. Among 15 samples 


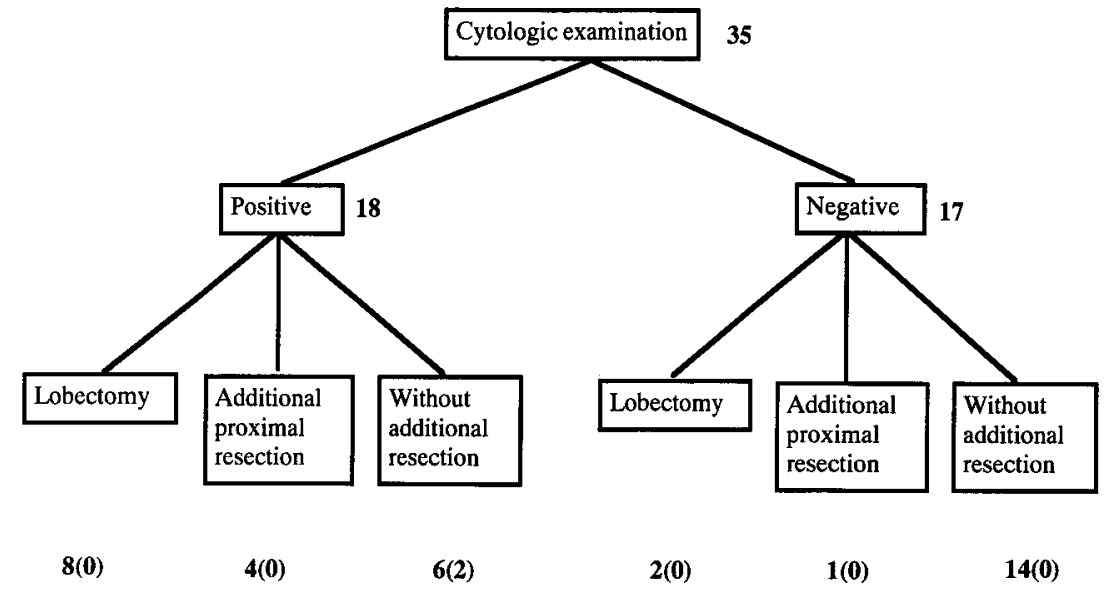

Fig 2. Operative procedures for tumor excision and outcome of marginal recurrence. Two recurrences on surgical margins occurred in cases of finally cytologically positive surgical margins. Conversely, no recurrences on surgical margins occurred in cases of cytologically negative surgical margins. Numbers of recurrences on surgical margin are described in parentheses.

showing histologically safe marginal distance (more than 10 $\mathrm{mm}), 40 \%$ (6/15) had cytologically positive margins.

Fig 2 describes the management protocol for the 35 tumors shown to be malignant by cytologic examination, as well as the eventual outcome. Among 18 malignant lesions with positive margins on cytologic study, 8 lesions were managed by residual lobectomy because excised undiagnosed tumor revealed lung cancer. When a solitary tumor was wedge resected with an insufficient surgical margin $(<5 \mathrm{~mm})$, an additional proximal parenchymal resection was performed except in high-risk candidates who had been treated by VATS. Among 6 patients who underwent excision of peripheral malignant tumor with positive cytologic margins, 2 recurrences developed in the tumor margins within 2 years. One tumor, in a 76-year-old patient with contralateral chronic empyema, was squamous cell carcinoma, $25 \mathrm{~mm}$ in maximum diameter, and was excised with a surgical margin of $15 \mathrm{~mm}$ by means of thoracotomy. The other tumor, in a 79-year-old patient, was metastatic colon cancer, $25 \mathrm{~mm}$ in maximum diameter, and was excised with a surgical margin of $1 \mathrm{~mm}$ by means of VATS.

Comment. It has been reported that approximately $30 \%$ of excised solitary malignant pulmonary tumors recur on the surgical margin. ${ }^{1-3}$ Therefore it is important to identify whether a malignant tumor has been resected completely. We assume that a malignant tumor has been resected with a safe margin when frozen section shows no evidence of malignancy. However, excised malignant tumors have recurred on the surgical margin despite histologically clean surgical margins. ${ }^{4}$ With cytologic examination, it is possible to harvest materials from the whole surgical margin. Therefore cytologic examination is also considered an effective means of detecting malignant cell contamination. In this study, $40 \%$ $(6 / 15)$ of samples with histologically safe surgical margins (more than $10 \mathrm{~mm}$ ) had cytologically positive surgical margins. In certain of these cases, malignant tumor recurred on these margins despite the clean histologic results.
A recent publication from the Canadian Lung Oncology Group ${ }^{5}$ maintained that margins of resection, whether histologically positive or negative, do not affect 3 -year survival or 3 -year recurrence rate. The recurrence rates described in this report were $40 \%(10 / 25)$ in patients with positive surgical margins and 49\% (184/374) in those with negative margins. However, inasmuch as the authors did not mention local recurrence, we cannot determine the local recurrence rate from their article. Moreover, they examined the surgical margins histologically. Had they used cytologic methods, it is likely that cytologically positive margins would have been discovered in patients with histologically negative margins. Tumor recurring on the surgical margin would be treated again in most cases. It would be significant if an improved disease-free interval could be demonstrated with this technique. If this method could predict local recurrence, it would be a guideline for adjuvant therapy.

In conclusion, cytologic examination of the surgical margins of wedge-resected malignant tumors was also useful to detect malignant cell contamination.

\section{REFERENCES}

1. Lung Cancer Study Group (prepared by Ginsberg RJ, Robinstein LV). Randomized trial of lobectomy versus limited resection for TINO non-small cell lung cancer. Ann Thorac Surg 1995;60:615-23.

2. Landreneau RJ, Sugarbaker JS, Mack MJ, et al. Wedge resection versus lobectomy for stage I ( $\mathrm{T} 1 \mathrm{~N} 0 \mathrm{M} 0$ ) non-small lung cancer. J Thorac Cardiovase Surg 1997;113:691-700.

3. Shennib HAF, Landreneau R, Mulder DS, et al. Video assisted thoracoscopic wedge resection of $\mathrm{T} 1$ lung cancer in high risk patients. Ann Surg 1993;218:555-60.

4. Downey RJ, McCormack P, LoCicero J III, et al. Dissemination of malignant tumors after video-assisted thoracic surgery: a report of twenty-one cases. J Thorac Cardiovasc, Surg 1996;111: 954-60.

5. Lasse $\mathrm{Y}$, Bucher HC, Wong E, et al. "Incomplete resection" in non-small cell lung cancer: need for a new definition. Ann Thorac Surg 1998;65:220-6. 